\title{
Effects of certain disinfectants and antibiotics on biofilm formation by Staphylococcus aureus isolated from medical devices at the University Hospital Center of Sidi Bel Abbes, Algeria
}

\author{
${ }^{* 1,2}$ Kara Terki, I., ${ }^{1}$ Hassaine, H., ${ }^{3}$ Kara Terki, A., ${ }^{4}$ Nadira, B., ${ }^{5}$ Kara Terki, N., ${ }^{1}$ Bellifa, S., \\ ${ }^{1}$ Mhamedi, I., and ${ }^{1,5}$ lachachi, $M$. \\ ${ }^{1}$ Laboratory of Food, Biomedical and Environnemental Microbiology (LAMAABE) \\ ${ }^{2}$ University of Djilali lyabes, Sidi Bel Abbes, Algeria \\ 3University Abou Bekr Belkaid, Tlemcen, Algeria \\ ${ }^{4}$ Ecole Supérieure de Management, Tlemcen, Algeria \\ ${ }^{5}$ University Belhadj Chouaib Ain Temouchent, Algeria \\ *Correspondence to: ibti.kara@gmail.com
}

\begin{abstract}
:
Background: Staphylococcus aureus is one of the species of bacteria most frequently isolated from medical devices. The ability to produce biofilm is an important step in the pathogenesis of these staphylococci infection, and biofilm formation is strongly dependent on environmental conditions as well as antibiotics and disinfectants used in the treatment and prevention of infections.

Methodology: In this study, $28 \mathrm{~S}$. aureus isolated from medical devices at the University Hospital Center of Sidi Bel Abbes in Northwestern Algeria were tested for biofilm formation by culture on Red Congo Agar (RCA). The tube method (TM) and tissue culture plate (TCP) techniques were also used to investigate the effect of penicillin, ethanol and betadine on pre-formed biofilm.

Results: Nineteen S. aureus isolates produced biofilm on the RCA and 7 produced biofilms by the tube method, 2 of which were high producer. In addition, 9 S. aureus isolates produced biofilm on polystyrene micro-plates, and in the presence of penicillin and ethanol, this number increased to 19 and 11 biofilm producing $S$. aureus isolates respectively. On the other hand, no biofilm was formed in the presence of betadine.

Conclusion: It is important to test for biofilm formation following an imposed external constraint such as disinfectants and antibiotics in order to develop new strategies to combat bacterial biofilms but also to better control their formation.
\end{abstract}

Keywords : Staphylococcus aureus, biofilm, medical device, disinfectant, antibiotic

\section{Effets de certains désinfectants et antibiotiques sur la formation de biofilms par Staphylococcus aureus isolé à partir de dispositifs médicaux au Centre Hospitalier Universitaire de Sidi Bel Abbès, Algérie}

\author{
*1,2 Kara Terki, I., ${ }^{1}$ Hassaine, H., ${ }^{3}$ Kara Terki, A., ${ }^{4}$ Nadira, B., ${ }^{5}$ Kara Terki, N., ${ }^{1}$ Bellifa, S., \\ ${ }^{1}$ Mhamedi, I., et 5 lachachi, $M$
}

${ }^{1}$ Laboratoire de microbiologie alimentaire, biomédicale et environnementale (LAMAABE)

Université de Djilali lyabes, Sidi Bel Abbès, Algérie

3Université Abou Bekr Belkaid, Tlemcen, Algérie

${ }^{4}$ Ecole Supérieure de Management, Tlemcen, Algérie

${ }^{5}$ Université Belhadj Chouaib Ain Temouchent, Algérie

*Correspondance à: ibti.kara@gmail.com 


\begin{abstract}
Abstrait:
Contexte: Staphylococcus aureus est l'une des espèces de bactéries les plus fréquemment isolées des dispositifs médicaux. La capacité de produire du biofilm est une étape importante dans la pathogenèse de ces infections à staphylocoques, et la formation de biofilm dépend fortement des conditions environnementales ainsi que des antibiotiques et des désinfectants utilisés dans le traitement et la prévention des infections. Méthodologie: Dans cette étude, 28 S. aureus isolés à partir de dispositifs médicaux au Centre hospitalier universitaire de Sidi Bel Abbès dans le nord-ouest de l'Algérie ont été testés pour la formation de biofilm par culture sur gélose rouge du Congo (RCA). La méthode des tubes (TM) et les techniques de plaques de culture tissulaire (TCP) ont également été utilisées pour étudier l'effet de la pénicilline, de l'éthanol et de la bétadine sur le biofilm préformé.

Résultats: Dix-neuf isolats de $S$. aureus ont produit un biofilm sur le RCA et 7 ont produit des biofilms par la méthode des tubes, dont 2 étaient très productifs. De plus, 9 isolats de $S$. aureus ont produit du biofilm sur des microplaques en polystyrène, et en présence de pénicilline et d'éthanol, ce nombre est passé à 19 et 11 isolats de $S$. aureus producteurs de biofilm respectivement. En revanche, aucun biofilm ne s'est formé en présence de bétadine.

Conclusion: Il est important de tester la formation de biofilm suite à une contrainte externe imposée comme les désinfectants et les antibiotiques afin de développer de nouvelles stratégies pour lutter contre les biofilms bactériens mais aussi pour mieux contrôler leur formation.
\end{abstract}

Mots-clés: Staphylococcus aureus, biofilm, dispositif médical, désinfectant, antibiotique

\title{
Introduction:
}

Staphylococcus aureus is a major cause of nosocomial and community-acquired infections. This organism is responsible for acute and chronic infections, most of which are due to the ability of the organism to adhere to medical implants and form biofilm (1). Biofilm is recognized as the most predominant form of bacteria development in nature, and is made of complex communities of microorganisms embedded in a selfsecreted matrix of extracellular polymeric substances (EPS) (2).

Biofilms form on the surface of most materials either biological or non-biological. According to the Center for Disease Control and Prevention (CDC), 65\% of bacterial infections are due to the presence of biofilms. In addition, infections associated with biofilms constitute a major clinical problem and are the cause of increased mortality, and generally associated with higher costs of medical treatment (3-5). The development of biofilms depends strongly on the environmental conditions in which they are formed, and the different parameters these biofilms are subjected to. Any change in these parameters is usually perceived as stress and can trigger a particular response within the biofilm (6).

It is therefore essential to study the response of biofilms to an imposed external constraint such as disinfectants and antibiotics, in order to develop adequate strategies to combat biofilms and also control and eventually limit their formation. The objectives of this study are to evaluate the capacity of $S$. aureus isolated from medical devices at the University Hospital of Side Bel Abbes, Algeria to adhere to surfaces and form biofilm, and to investigate the influence of some disinfectants and antibiotics on the formation of biofilms.

\section{Materials and methods:}

\section{Study setting and bacterial isolates}

The $S$. aureus strains used in this study were isolated from medical devices at the Departments of Reanimation, Urology and Internal Medicine of the University Hospital Center ( $\mathrm{CHU})$, Sidi Bel Abbes, a city located in northwestern Algeria.

\section{Isolation/identification of $\boldsymbol{S}$. aureus isolates}

After ablation of the medical devices, the microbiological analysis was carried out using the "Brun-Buisson" technique (7) which consists of rinsing the catheter lumen with saline solution and vortexing this content out through its intravascular end for culture on Chapman agar medium for selective growth isolation of staphylococci. Identification of $S$. aureus was done by conventional methods including colony morphology, Gram stain reaction, catalase production, and coagulase assay, and by the API STAPH system (Bio

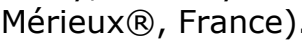

\section{Detection of biofilm formation by Red Congo Agar (RCA) method}

The Congo Red test was performed as previously described by Freeman et al., (8), which is based on the ability of the Congo Red dye to directly interacts with certain polysaccharides, forming colored complexes (9). The medium consisted of Brain Heart infusion broth (BHIB, 37g/L), sucrose $(50 \mathrm{~g} / \mathrm{L})$, agar no. $1(10 \mathrm{~g} / \mathrm{L})$ and Congo Red stain $(0.8 \mathrm{~g} / \mathrm{L})$. The freshly prepared Congo Red agar plates were inoculated and incubated aerobically for 24 to $48 \mathrm{~h}$ at $37^{\circ} \mathrm{C}$. 
Biofilm producers form black colonies on CRA, while non-producers formed red colonies.

\section{Detection of biofilm formation by tube method This technique, developed in 1982 by} Christensen et al., (11) provides a qualitative assessment of the biofilm formation. From a young culture of $24 \mathrm{~h}$, a colony is grown in $10 \mathrm{~mL}$ brain heart infusion broth (BHIB) supplemented with $2 \%$ sucrose. After incubation at $37^{\circ} \mathrm{C}$ for 24 hours, the tubes were washed with phosphate buffered saline (PBS) at pH7.3, and then dried. Each tube was then stained with crystal violet $(0.1 \%)$ for 5 minutes. Once the dye is removed, the tubes were washed with distilled water and allowed to dry. Biofilm is considered formed when a visible film doubles the wall of the tube as well as its bottom. The formation of a ring at the liquid interface is not indicative of biofilm formation (11).

\section{Detection of biofilm formation by Tissue Culture Plate (TCP) method}

Quantitative determination of biofilm formation in 96-well microplates was performed according to Christensen et al., (10) with slight modification by extending the incubation time to 48 hours. After culturing the bacterial strains in the BHIB medium and incubating for $18 \mathrm{~h}$ at $37^{\circ} \mathrm{C}$, the mixture was diluted $1 / 100$ in fresh BHIB medium. The wells of a 96 microtiter plates were then filled with $0.2 \mathrm{ml}$ of this dilution and incubated at $37^{\circ} \mathrm{C}$. The microplate wells were washed 3 times with distilled water, dried in an inverted position, and stained with $0.5 \%$ (p:v) crystal violet solution. The adherent cells were resuspended in $95 \%$ ethanol solution and the absorbance measured at $540 \mathrm{~nm}$ using an ELISA autoreader (Model 680, Biorad, UK). The isolates were then classified into three categories as: (a) non adhering, with an optical density less than 0.120; (b) weakly adhering, with an optical density greater than 0.120 but less than or equal to 0.240 and (c) strongly adhering, with an optical density greater than 0.240 .

Effects of antiseptics and antibiotics on biofilm formation using the TCP technique

The antiseptics tested in this study were the main ones used at the Hospital University Center of Sidi Bel Abbes, which are polyvidone iodine (PVPI), marketed as $10 \%$ Betadine $\AA$ (Laprophan Laboratory) and 70\% ethyl alcohol prepared at the laboratory of the hospital pharmacy of the University Hospital. The antibiotic tested was penicillin G (1 million unit) which is marketed by SAIDAL laboratories.

After forming a 48-hour young biofilm by the TCP technique (as previously described), the 96-well microplate was rinsed
3 times with distilled water and dried. Then, Penicillin G (1 million unit), betadine 10\% (an iodinated derivative) and $70 \%$ ethyl alcohol were added to the biofilm. The microplate was incubated for 24 hours. After incubation, the wells of the microplate were carefully rinsed, dried and stained with crystal violet according to the standard technique. The optical density (OD) was measured at 490 $\mathrm{nm}$ by the ELISA autoreader.

\section{Results:}

Biofilm formation by the different methods

A total of $28 \mathrm{~S}$. aureus isolates were identified by conventional biochemical test and the API 20 Staph identification. Nineteen of the $28 \mathrm{~S}$. aureus isolates produced biofilm (slime) by the CRA method, showing black colonies with dry crystalline consistency from production of exopolysaccharide that reacted with the Congo Red dye. By the tube method, only $7 \mathrm{~S}$. aureus isolates produced biofilm, of which 2 were high producers (Table 1 ). The quantitative determination of biofilm formation by the TCP using the BHIB growth medium (Fig 1 ) shows that only 9 S. aureus isolates produced biofilm, with 7 of them were low producers and 2 high producers (Table 1).

\section{Effects of antiseptics and antibiotic on biofilm formation by TCP method}

Eleven $S$. aureus isolates produced biofilm in the presence of ethanol (70\% ethyl alcohol) with 3 high and 8 moderate biofilm producers while $19 \mathrm{~S}$. aureus isolates produced biofilm in the presence of penicillin (1mu) with 8 high and 11 moderate biofilm producers (Table 1 and Fig 1 ). On the other hand, no $S$. aureus isolate formed biofilm in the presence of betadine.

\section{Discussion:}

Staphylococcus aureus is one of the most common microorganisms responsible for infections of foreign body such as central venous catheters, mechanical heart valves and urinary catheters. Their major virulence factors are the ability to produce an extracellular matrix and form biofilm, which makes clinical treatment extremely difficult (12). Early detection of staphylococcal biofilms may be one of the essential steps for the prevention and treatment of infections of medical devices (13).

The finding of this study revealed that 19 of the $28(67.9 \%)$ S. aureus isolates produce biofilm (slime) by culture on Congo Red agar, which agrees with $60.8 \%$ reported by Arciola et al., (14). Biofilm (slime) production give the appearance of black colo- 
Table 1: Results of biofilm formation by Staphylococcus aureus isolated from medical devices.

\begin{tabular}{|c|c|c|c|c|c|c|c|c|}
\hline \multirow[t]{2}{*}{ Isolate } & \multirow[t]{2}{*}{ Unit } & \multirow{2}{*}{$\begin{array}{c}\text { Medical } \\
\text { device }\end{array}$} & \multicolumn{4}{|c|}{ TCP } & \multirow[t]{2}{*}{ TM } & \multirow{2}{*}{$\begin{array}{l}\text { Production } \\
\text { of biofilm }\end{array}$} \\
\hline & & & BHIB & Ethanol & Penicillin & Betadine & & \\
\hline $\mathrm{S} 1$ & Urology & U.C & - & ++ & ++ & - & - & + \\
\hline S2 & Urology & U.C & - & - & ++ & - & - & + \\
\hline s3 & Urology & U.C & - & - & ++ & - & - & + \\
\hline S4 & Urology & U.C & + & + & ++ & - & + & + \\
\hline S5 & Urology & U.C & - & - & + & - & + & + \\
\hline s6 & Urology & U.C & - & - & - & - & - & + \\
\hline S7 & Urology & U.C & - & - & + & - & - & + \\
\hline S8 & Urology & U.C & - & - & - & - & - & - \\
\hline s9 & Urology & U.C & - & - & - & - & - & - \\
\hline $\mathrm{S} 10$ & Urology & U.C & - & - & - & - & - & - \\
\hline $\mathrm{S} 11$ & Urology & U.C & - & - & + & - & - & - \\
\hline S12 & Urology & U.C & + & + & ++ & - & + & + \\
\hline $\mathrm{S} 13$ & Urology & U.C & - & - & - & - & - & - \\
\hline S14 & Intensive care & C.V.C & - & - & + & - & - & - \\
\hline S15 & Intensive care & C.V.C & - & - & - & - & - & - \\
\hline S16 & Intensive care & C.V.C & - & - & - & - & - & - \\
\hline $\mathrm{S} 17$ & Intensive care & C.V.C & - & - & + & - & - & + \\
\hline S18 & Intensive care & C.V.C & - & + & ++ & - & + & + \\
\hline S19 & Intensive care & C.V.C & - & + & ++ & - & + & + \\
\hline S20 & Intensive care & C.V.C & - & - & - & - & - & + \\
\hline $\mathrm{S} 21$ & Intensive care & C.V.C & - & + & + & - & - & + \\
\hline $\mathrm{S} 22$ & Intensive care & C.V.C & ++ & ++ & + & - & ++ & + \\
\hline $\mathrm{S} 23$ & $\begin{array}{l}\text { Internal } \\
\text { Medicine }\end{array}$ & U.C & + & + & + & - & - & + \\
\hline S24 & $\begin{array}{l}\text { Internal } \\
\text { Medicine }\end{array}$ & U.C & + & + & ++ & - & - & + \\
\hline $\mathrm{S} 25$ & $\begin{array}{l}\text { Internal } \\
\text { Medicine }\end{array}$ & U.C & + & + & + & - & - & + \\
\hline S26 & $\begin{array}{l}\text { Internal } \\
\text { Medicine }\end{array}$ & C.V.C & - & - & - & - & - & + \\
\hline S27 & $\begin{array}{l}\text { Internal } \\
\text { Medicine }\end{array}$ & C.V.C & - & - & + & - & - & + \\
\hline $\mathrm{S} 28$ & $\begin{array}{l}\text { Internal } \\
\text { Medicine }\end{array}$ & C.V.C & ++ & ++ & + & - & ++ & + \\
\hline
\end{tabular}

C.V.C: central venous catheters, U.C: urinary catheters, $(++)$ : biofilm formation good, $(+)$ : biofilm formation average; (-): non biofilm formation

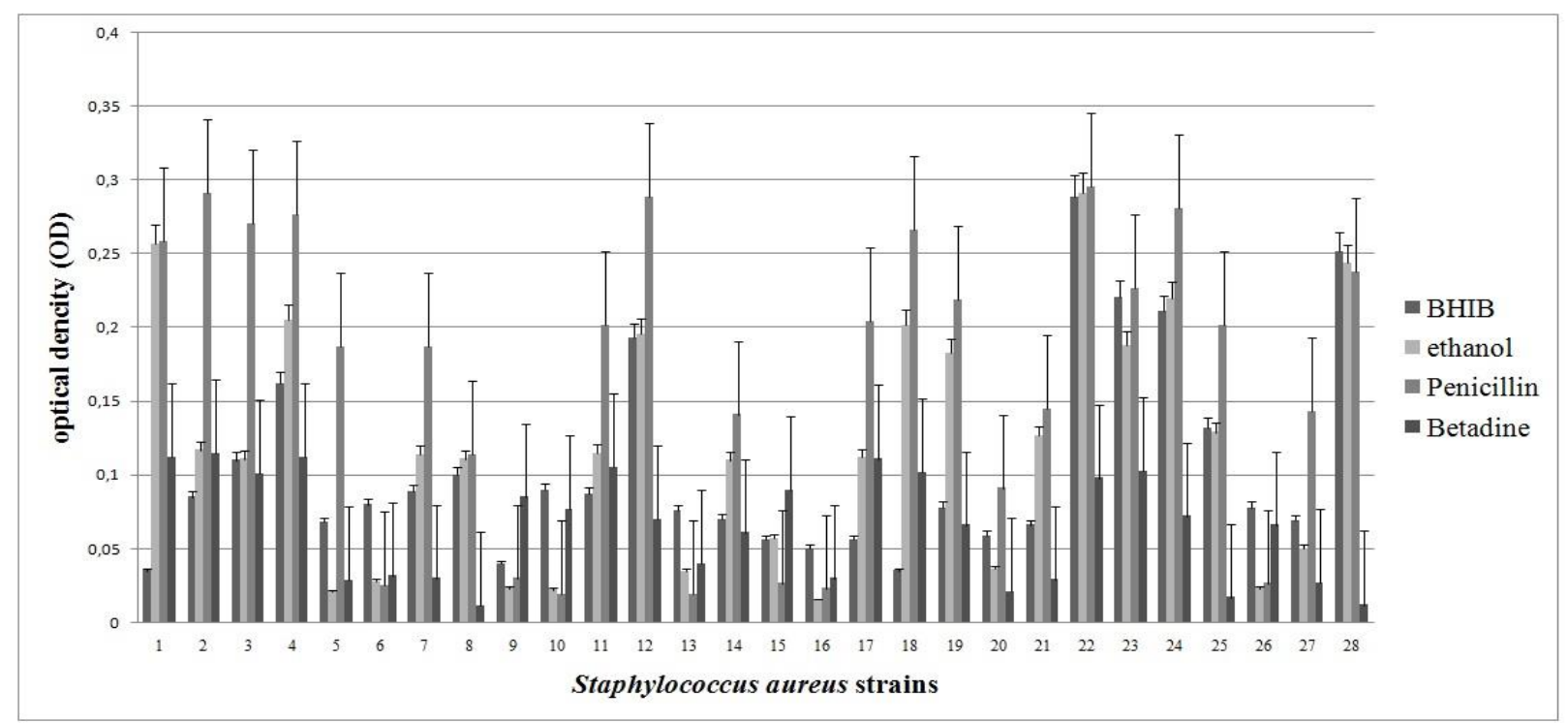

Fig 1: Biofilm formation of Staphylococcus aureus strains on BHIB, ethanol 70\%, Penicillin and betadine $10 \%$. Adherent bacterial biofilms were stained with Crystal violet as described in Materials and methods. A strain was considered biofilmpositive, if its OD was higher or equal to $0.120 ; p<0: 05$ (t-test). Data are representative of 3 replicate experiments.

nies on Congo Red agar and is mainly due to the production of polysaccharide intercellular adhesin (PIA) that reacts with the culture medium. Described for the first time in Staphylococcus epidermidis by Mack et al., (15), the PIA-encoded by ica locus, is 
generally located on the surface of the cell, and plays an important role in intercellular adhesion. PIA has been recognized as a crucial factor in the colonization of medical equipment by staphylococci $(12,13,16)$.

The result obtained by the TCP technique revealed that only 9 of the 28 $(32.1 \%)$ S. aureus isolates produced biofilm in the BHIB medium. These results are in agreement with the observations of other authors who have shown that few strains are biofilm-forming in a growth medium without supplement such as (sugar, antibiotics or $\mathrm{NaCl}(11,17,18)$. In this study, 7 of the 28 $(25 \%) S$. aureus isolates produced biofilm by the tube method (TM) and a good correlation was noted between the TCP and TM for high biofilm producing isolates. However, there was a wide variability in biofilm classification by the TM method and difficulty in differentiating between low biofilm producing and non-producing isolates. Therefore, the present study agrees with the findings of other authors including Mathur et al., (11), TM method for routine detection of biofilm is not recommended. Consequently, the TCP technique is considered the 'gold standard' test for the detection of biofilm formation, and has been recognized as the most sensitive, accurate and reproducible method for detection of staphylococcal biofilm formation. It also allows for quantitative assessment in order to compare the adhesion of different strains and to examine large number of isolates simultaneously (19), as well as allows for the identification of optimal culture factors and conditions for biofilm formation (20).

Biofilm formation is a complex phenomenon, which can be affected by many factors, particularly the surrounding environment (21). In order to study the influence of certain factors in the surrounding environment at the Hospital University Center of Sidi Bel Abbes on biofilm formation in $S$. aureus, the TCP technique was selected for testing the effects of two commonly used antiseptics (ethanol and betadine) and penicillin G. We observed that after addition of penicillin and ethanol, the number of biofilm-forming $S$. aureus isolates increased to 19 and 11 respectively. These observations are consistent with those from other studies $(11,22)$, which suggest a strong dependence between growth conditions and biofilm formation in staphylococci. Luther et al., (23) and Redelman et al., (24) observed in their studies that ethanol encouraged biofilm formation in all strains studied. Similarly, ElBanna et al., (25) observed that antibiotics promote biofilm formation in staphylococci isolated from medical devices at University Hospital Center of Alexandria City in Egypt. Based on our 2013 results (2) and those of others in the literature, it has been found that the expression of ica operon depends on environmental conditions such as growth media composition, temperature, osmolarity, the presence of oxygen and subinhibitory concentrations of antibiotics. High concentrations of $\mathrm{NaCl}$ also increase biofilm formation by strongly inducing ica operon expression in staphylococci. The presence of divalent cations such as calcium and magnesium, increases the production of polysaccharides, which leads to amplification of biofilm formation. In staphylococci, the expression of the ica ADBC genes can also be influenced by other environmental conditions such as oleic acid and iron limitation $(12,26,27)$.

On the other hand, the resistance of biofilm-forming bacteria to antibiotics and disinfectants is well acknowledged. According to some authors, resistance is attributed to factors such as bacteria physiology, power of matrices, and other factors (28). Repeated exposure to disinfectants and antibiotics can generate some physiological adaptations that further delay the subsequent tolerance of the biofilm. When a community of adherent bacterial cells was subjected to antibiotics and disinfectants, only a few were able to resist them (33). On the other hand, in the presence of betadine (polyvidone iodine), the optical density decreases in all the isolates and none of them was able to form a biofilm.

The results of Essayagh et al., (34) agrees with ours that polyvidone iodine (PVPI) is the best of antiseptics studied. In fact, only $6(4.6 \%)$ out of the 130 strains tested in their study could resist PVPI that was available at the pharmacy while 40 $(30.7 \%)$ were resistant to iodinated alcohol and $20(15.4 \%)$ to $70 \%$ alcohol. Chemical analysis has previously confirmed this finding (35). Indeed, PVPI is a stable molecule consisting of an iodine complex and a watersoluble organic agent that slowly transports and releases iodine. This structure makes the PVPI less irritating and allergenic, and more stable over time while iodized alcohol and $70 \%$ ethyl alcohol are stable only over fifteen days and one month respectively after the date of their preparations $(35,36)$.

\section{Conclusion:}

S. aureus isolates exposed to clinically relevant concentrations of ethanol increase biofilm formation, however, no strain formed biofilm in the presence of betadine. Future research should determine the impact of our findings on various alcohol preparations used in the management and prevention of clinical infections caused by biofilm forming staphylococci. 


\section{References:}

1. Verma, P., and Singh, S. Clinical distribution of biofilm forming Staphylococcus aureus and its sensitivity against some antibiotics. World Pharm Pharmaceut Sci. 2015; 4 (4): 942-952

2. Kara Terki, I., Hassaine, H., Oufrid, S., Bellifa, S., Mhamedi, I., Lachachi, M., and Timinouni, M. Detection of icaA and icaD genes and biofilm formation in Staphylococcus spp. isolated from urinary catheters at the University Hospital of Tlemcen (Algeria). Afr J Microbiol Res. 2013 ; 7 (47): 5350-5357.

doi: $10.5897 /$ AJMR2013.5873

3. Bellifa, S., Hassaine, H., Kara Terki, I., et al. Study of Biofilm Production and Antimicrobial Resistance Pattern of Klebsiella pneumoniae Isolated from Urinary Catheter at the University Hospital of Tlemcen. Am J Microbiol Biotechnol. $2016 ; 3$ (2): 13-17

http://www.aascit.org/journal/ajmb

4. Chessa, D., Ganau, G., Spiga, L., Bulla, A., Mazzarello, V., Campus, G. V., and Rubino, S. Staphylococcus aureus and Staphylococcus epidermidis Virulence Strains as Causative Agents of Persistent Infections in Breast Implants. PLoS One. 2016; 26 : 11 (1): e0146668.doi:10.1371/journal.pone.0146668

5. Badran, H., Salah, M., Fawzy, M., Sayed, A., and Ghaith, D. Detection of Bacterial Biofilms in Chronic Pharyngitis Resistant to Medical Treatment. Ann Otol Rhinol Laryngol. 2015; 124 (7): $567-571$

doi: $10.1177 / 0003489415570934$.

6. Ouchar Mahamat, O., Tidjani, A., Savadogo, A. Abakabir Mahamat, A., Somda, M. K., and Traore, A. S. Isolement et caracterisation des bacteries productrices des biofilms issues des produits alimentaires. Rev Microbiol Ind San et Environ. 2013; 7 (2): 187 - 210.

7. Brun-Buisson, C. Analyse critique des méthodes diagnostiques d'infection liée au cathéter sur matériel enlevé. Réan Urg. 1994; 3: 343-346. Freeman, D. J., Falkner, F. R., and Keane, C. T. New method for detecting slime production by coagulase-negative staphylococci. J Clin Pathol. 1989;42:872-874

http://dx.doi.org/10.1136/jcp.42.8.872

9. Jain, A., and Agarwal, A. Biofilm production, a marker of pathogenic potential of colonizing and commensal staphylococci. J Microbiol Methods. 2009; 76: 88-92. doi: 10.1016/j.mimet.2008.09.017

10. Christensen, G. D., Simpson, W. A., and Yonger, J. J., Adherence of coagulase - negative staphylococci to plastic tissue culture plates: a quantitative model for the adherence of staphylococci to medical devices. J Clin Microbiol. 1985; 22: 996-1006.

11. Mathur, T., Singhal, S., Khan, S., Upadhyay, D. J., Fatma, T., and Rattan, A. Detection of biofilm formation among the clinical isolates of staphylococci: an evaluation of three different screening methods. Indian J Med Microbiol. 2006; 24 (1): 25-29.

doi: $10.4103 / 0255-0857.19890$

12. Derek, E., Moormeier, K., and Bayles, W. Staphylococcus aureus biofilm: a complex developmental organism. Mol Microbiol. 2017;104(3):365-376.

doi: $10.1111 / \mathrm{mmi} .13634$

13. Martín-López, J. V., Pérez-Roth, E., Díez Gil, F. C. M. O., Batista, N., Morales, M., and MéndezÁlvarez, S. Detection of Staphylococcus aureus clinical isolates harboring the ica gene cluster needed for biofilm establishment. J Clin Microbiol.2002;40(4):1569-1570

doi:10.1128/JCM.40.4.1569-1570.2002

14.

Arciola, C. R., Baldassarri, L., and Montanaro, L. Presence of icaA and icaD genes and slime production in a collection of staphylococcal strains from catheter-associated infections. J
Clin Microbiol. 2001; 39: 2151 - 2156. doi:10.1128/JCM.39.6.2151-2156.2001

15. Mack, D., Siemssen, N., and Laufs, R. Parallel induction by glucose of adherence and a polysaccharide antigen specific for plasticadherent Staphylococcus epidermidis: evidence for functional relation to intercellular adhesion. Infect Immunol. 1992; 60: 2048-2057.

16. Cramton, S. E., Ulrich, M., and Gotz, F. Anaerobic conditions induce expression of polysaccharide intercellular adhesin in Staphylococcus aureus and Staphylococcus epidermidis. Infect Immunol. 2001; 69: 40794085. doi: 10.1128/IAI.69.6.4079-4085.2001

17. Cho, S., Naber, K., Hacker, J., and Ziebuhr, W. Detection of the ica ADBC gene cluster and biofilm formation in Staphylococcus epidermidis isolates from catheter-related urinary tract infections. Int Antimicrob. Agent. 2002; 19: 570 -575. https://doi.org/10.1016/S0924-8579 (02)00101-2

18. Johannes, K. M. Knobloch, M. A , Horstkotte, H., and Dietrich, M. Evaluation of different detection methods of biofilm formation in Staphylococcus aureus. Med Microbiol Immunol. 2002; 191: 101-106.doi :10.1016/j.mimet.2008.09.017

19. Racha, A. N., Abu Shady, H. M., and Hussein, H. $\mathrm{S}$. Biofilm formation and presence of icaAD gene in clinical isolates of staphylococci. Egyptian Journal of Médical Human and Genetics. 2012; 13:269-274. http://dx.doi.org/10.1016/j.ejmhg.2012.04.007

20. Castro Melo, P., Ferreira, L. M., Filho, A. N., Zafalon, L. F., Godoy Vicente, H. I., and de Souza, V. Comparison of methods for the detection of biofilm formation by Staphylococcus aureus isolated from bovine sub-clinical mastitis. Braz Microbiol. 2013; 44 (1): 1517 - 1522. http://dx.doi.org/10.1590/S1517-83822013005000031

21. Branger, A., Richer, M. M., and Roustel, S. Quelque systéme microbien: les biofilms. Dans: Microbiochimie et alimentation. Educagri édition, Dijon. 2007: 131-164.

22. Kevin, D., Mlynek, A., and Mary, T., Effects of Low-Dose Amoxicillin on Staphylococcus aureus USA300 Biofilms. Antimicrob Agents Chemother. 2016;60:2639-2651.doi:

23. Luther, M. K., Bilida, S., Leonard, A., Mermel., and Kerry., L. Ethanol and Isopropyl Alcohol Exposure Increases Biofilm Formation in Staphylococcus aureus and Staphylococcus epidermidis. Infect Dis Ther. 2015; 4 (2): 219226. doi: $10.1007 / \mathrm{s} 40121-015-0065-y$

24. Redelman, C. V., Maduakolam, C., Gregory, G., and Anderson. Alcohol treatment enhances Staphylococcus aureus biofilm Development. FEMS Immunol Med Microbiol. 2012; 66: 411418. doi:10.1111/1574-695x.12005

25. El-Banna, T., Abd El-Aziz, A., Abo-Kamar, A., Ghazal, A., and Abo Zahra, R. In vitro activities of three kinds of antibiotics against staphylococcal biofilm and planktonic cultures. Afr J Microbiol Res. 2010; 4 (21): 2275-2282. http://www.academicjournals.org/ajmr

26. Gotz, F. Staphylococcus and biofilms. Mol Microbiol. 2002; 43: 1367 - 1378. https://doi.org/10.1046/j.1365-2958.2002.02827.x

27. Chaieb, K., Mahdouania, K., and Bakhrouf, A. Detection of icaA and icaD loci by polymerase chain reaction and biofilm formation by Staphylococcus epidermidis isolated from dialysate and needles in a dialysis unit. J Hosp Infect. $2005 ; 61: 225-230$.

doi: $10.1016 / j . j h i n .2005 .05 .014$

28. Olsen, I. Biofilm-specific antibiotic tolerance and resistance. Eur J Clin Microbiol Infect Dis. 2015; 34(5):877-886.doi:10.1007/s10096-015-2323-z Abdel Halim, R. M., Kassem, N. N., and Mahmoud, B. S. Detection of Biofilm Producing Staphylococci among Different Clinical Isolates and Its Relation to Methicillin Susceptibility. Macedonian Journal of Medical Sciences. 2018; 
$20 ; 6(8): 1335-1341$.

doi.org/10.3889/oamjms.2018.246

30. Stewart, P. Antimicrobial Tolerance in Biofilms. Microbiol Spectr. 2008; 3 (3): 10.1128. doi:10.1128/microbiolspec.MB-0010-2014

31. Thien-Fah C, M., and O'Toole, G. A. Mechanisms of biofilm resistance to antimicrobial agents. Trends Microbiol 2001

https://doi.org/10.1016/S0966-842X(00)01913-2

Wojtyczka, R., Orlewska, K., Kępa, M., Idzik, D., Dziedzi, A., Mularz, T, and Wąsik, T. J. Biofilm formation and antimicrobial susceptibility of Staphylococcus epidermidis strains from a hospital environment. Int J Environ Res Publ HIth 2014;11(5):4619-4633

doi: $10.3390 /$ ijerph110504619

33. Amiyare, R., Esmail, A., Ghanmi, Y., and Ouhssine, M. Evaluation de l'effet d'un désinfect- ant à base de Glutaraldehydeà $2 \%$ sur le biofilm d'Acinetobacter baumannii. J Mater Environ Sci. 2015; 6 (11): 3168 - 3173

34. Essayagh, T., Elameri, A., Zohoun, A.,, Miloudi,

M., and Elhamzaoui, S. Activité antibactérienne des antiseptiques utilisés à I'Hôpital militaire d'instruction Mohamed V de Rabat. Ann Biol Clin. 2010;68(4):421-427.

doi: $10.1684 / a b c .2010 .0447$

35. Clevenot, D., Robert, S., Debaene, B., and Mimoz, O. Analyse critique de la littérature sur I'utilisation comparée de deux antiseptiques lors du cathétérisme vasculaire ou rachidien. Ann Fr Anesth. 2003; 22: 787-797.

36. Vaillant, L. Les antiseptiques, ce n'est pas automatique. Annal Dermatol. 2005; 132: 942952. 